DOI: $10.20472 /$ IAC.2019.047.018

\author{
MARIKA ROBINSON \\ St. Petersburg College , United States
}

SARA BIANCO

University of Cincinnati, United States

ADONIA K. SMITH

ASL Rose, United States

\title{
OLDEST SCHOOLS FOR THE DEAF: SIGNED LANGAUGES ARE THE KEY
}

\begin{abstract}
:
This presentation will cover the early history of the first few public schools for the Deaf in the world and the far-reaching impact of these schools on the languages and communities of Deaf peoples. We will discuss events leading to the founding of Deaf schools and how these early schools contributed to the formation of over four hundred signed languages. Research shows that language and schools are vital to a child's educational and social development. Language acquisition early in life and continuous learning in signed languages become a springboard to academic and social achievement for Deaf people. As the world moves rapidly toward multilingualism and cultural competency, the trend in Deaf education has moved in the opposite direction. Events in 1880 redirected teaching through signed languages to the over-emphasis on speaking and listening in the majority language, stunting a Deaf person's chances at success and leading to the prevalence of language deprivation. Schools for the Deaf and signed languages are currently under threat. Preserving these schools becomes even more urgent. Through a literature review justifying the benefits of signed languages in schools for the Deaf, we will present the case for more support to schools for the Deaf.
\end{abstract}

\section{Keywords:}

Deaf, signed languages, history, preservation, education 